\title{
Sphere-forming assay vs. organoid culture: Determining long-term stemness and the chemoresistant capacity of primary colorectal cancer cells
}

\author{
HUI ZHAO ${ }^{1,2^{*}}$, CHANG YAN ${ }^{1,3^{*}}$, YIBING HU ${ }^{1,3}$, LEI MU ${ }^{1,3}$, KAIYU HUANG ${ }^{1}$, \\ QILING LI ${ }^{1,2}$, XIAOLAN LI ${ }^{1}$, DEDING TAO ${ }^{1}$ and JICHAO QIN ${ }^{1,3}$ \\ ${ }^{1}$ Molecular Medicine Center, and Departments of ${ }^{2}$ Stomatology and ${ }^{3}$ Surgery, Tongji Hospital, \\ Tongji Medical College, Huazhong University of Science and Technology, \\ Wuhan, Hubei 430030, P.R. China
}

Received October 24, 2018; Accepted December 21, 2018

DOI: 10.3892/ijo.2019.4683

\begin{abstract}
Three-dimensional (3D) cultures are indispensable for capturing tumor heterogeneity in colorectal cancer (CRC) in vitro. Although $3 \mathrm{D}$ cultures (such as sphere-forming assay and organoid culture) can partially preserve the morphological and molecular characteristics of primary CRC, whether these 3D cultures maintain the long-term stemness of cancer stem cells (CSCs) remains largely unknown. In the present study, spheres and organoids were generated side by side using individual primary CRC specimens, then respectively processed as serial passages. The results revealed that during serial passages, the percentage of CSCs (such as cluster of differentiation- $133^{+}$and $\mathrm{Wnt}^{+}$cells) in organoids and the tumor-initiating capacity of organoid-derived cells were constant, while they gradually increased in the sphere-derived cells. Furthermore, during serial passages, resistance to chemotherapeutic agents (including 5-fluorouracil and oxaliplatin) in sphere- and organoid-derived cells was evaluated. The results indicated that the percentage of chemoresistant cells was constant in serial organoid cultures; however, it gradually increased in the serial sphere-forming assays. Taken together, the results of the present study comprehensively demonstrate that, with regard to long-term culture in vitro, organoid culture may be useful in maintaining tumor heterogeneity and the levels of chemoresistant cells,
\end{abstract}

Correspondence to: Dr Jichao Qin, Department of Surgery, Tongji Hospital, Tongji Medical College, Huazhong University of Science and Technology, 1095 Jiefang Avenue, Wuhan, Hubei 430030, P.R. China

E-mail: jcqin@tjh.tjmu.edu.cn

${ }^{*}$ Contributed equally

Key words: organoid, sphere, colorectal cancer, cancer stem cells, Wnt, chemoresistance while the sphere formation assay enriches for CSCs and chemoresistant cells.

\section{Introduction}

Colorectal cancer (CRC) is the third most common cause of cancer-associated mortality worldwide (1). A number of studies have revealed that CRC is heterogeneous, manifesting with variegated cellular morphologies, histopathology and chemoresistant capacity; these biological characteristics of CRC have contributed to the failure of conventional therapeutics (2-4). In order to improve the prognosis of patients with CRC, preclinical tumor models are essential for simulating primary tumors, exploiting novel therapeutic approaches and predicting drug responses in vivo (5). Even though preclinical models have been widely used, their advantages and limitations remain largely unknown.

It has been suggested that cancer stem cells (CSCs) may be responsible for tumor heterogeneity (6). In CRC, it has been revealed that the tumor bulk exhibits cellular hierarchy with CSCs at the apex, possessing self-renewal abilities, multi-differentiation potential and an inherent chemoresistant capacity (7). In addition, tumor recurrence in patients with CRC is closely associated with the presence of CSCs in tumors (8). These findings indicate that CSCs may be promising therapeutic targets. Therefore, the long-term maintenance of stem cell-like properties in preclinical models is critical for capturing the real primary tumor conditions.

Three dimensional (3D) cultures, such as sphere formation assays and organoid culture, can be used as platforms that support the long-term expansion of primary tumor cells (9). However, whether these 3D models can preserve the original properties of parental tumors remains unclear. Sphere formation assays, for instance, have been reported to expand CSCs during serial passages, and thus they are not a suitable platform for investigating drug activity (10). Organoid culture, on the other hand, has been exploited for predicting drug efficacy in vivo (11-14). However, it is still unclear whether the stem cell-like properties would be maintained long-term in organoid culture. 
The present study generated sphere and organoid cultures side by side using individual CRC specimens and demonstrated that: i) The sphere formation assay was enriched for CSCs, while the organoid culture only maintained CSCs; and ii) the frequency of chemoresistant CRC cells in each of the generations during the serial organoid passages were almost same; however, the serial sphere formation assay increased the frequency of chemoresistant cells.

\section{Materials and methods}

Collection of CRC specimens and preparation of the single cell suspension. Surgical human colorectal adenocarcinoma samples were obtained with written informed consent and approval from the Institutional Review Board of Tongji Hospital, Tongji Medical College, Huazhong University of Science and Technology (Wuhan, China; IRB ID: 20141106); the experiments were conducted according to the principles of the Declaration of Helsinki. In total, 20 tumor specimens from CRC patients were included in the present study, and the patients were assigned case numbers CRC1-20. The patient clinical characteristics are listed in Table SI. The CRC specimens were disassociated into single primary CRC cells as described previously (15). Briefly, fresh specimens were minced into small sections with scissors. The completely minced pieces were then incubated in serum-free Dulbecco's modified Eagle's medium (DMEM)/F12 (Thermo Fisher Scientific, Inc., Waltham, MA, USA) containing $1.5 \mathrm{mg} / \mathrm{ml}$ collagenase IV (Gibco; Thermo Fisher Scientific, Inc.), $20 \mu \mathrm{g} / \mathrm{ml}$ hyaluronidase (Sigma-Aldrich; Merck KGaA, Darmstadt, Germany) and $1 \%$ penicillin/streptomycin (Thermo Fisher Scientific, Inc.) at $37^{\circ} \mathrm{C}$ for 1 to $2 \mathrm{~h}$. To eliminate red blood cells, the cells were incubated in red blood cell lysis buffer (eBioscience; Thermo Fisher Scientific, Inc.) on ice for $10 \mathrm{~min}$, then washed twice with PBS. The single primary CRC cells were then resuspended in PBS for use in subsequent organoid culture, sphere forming assay and animal studies.

Organoid culture. Organoid culture was processed as previously described $(15,16)$, with several modifications. For culture establishment, single primary CRC cells were embedded in Matrigel (growth factor reduced; phenol free; BD Biosciences, Franklin Lakes, NJ, USA) and seeded into 24-well culture plates at the indicated dosage $(1,000$ cells/30 $\mu 1$ Matrigel/well). Following Matrigel polymerization, the cells were overlaid with human colorectal cancer organoid culture medium and incubated at $37^{\circ} \mathrm{C}$ in humidified air containing $5 \% \mathrm{CO}_{2}$. The composition of the human colorectal cancer organoid culture medium was as follows: DMEM/F12 (Invitrogen; Thermo Fisher Scientific, Inc.) supplemented with 1X B27 (Invitrogen; Thermo Fisher Scientific, Inc.), $50 \mathrm{ng} / \mathrm{ml}$ recombinant human EGF (Sigma-Aldrich; Merck KGaA), 10 nM Gastrin (Sigma-Aldrich; Merck KGaA) and 500 nM A83-01 (Tocris Bioscience, Bristol, UK) (16). The medium was changed every 3 days. To calculate the forming efficiency, following 7 days post-embedding, organoids with diameters $>100 \mu \mathrm{m}$ were scored under an inverted microscope (Leica Microsystems, Wetzlar, Germany). The forming efficiency $(\%)=$ scored organoid number $/$ total embedding CRC cells. For serial passages, following 7 days post-embedding, whole organoids were trypsinized using $0.025 \%$ trypsin/EDTA at $37^{\circ} \mathrm{C}$ for $15-20 \mathrm{~min}$. Single organoid-derived cells were then resuspended with PBS and employed for a new round of organoid culture in Matrigel.

Sphere formation assay. The sphere formation assay was conducted as previously described $(17,18)$. Single primary CRC cells were resuspended in standard stem cell medium (SCM), which consisted of the following: DMEM/F12 (Invitrogen; Thermo Fisher Scientific, Inc.) supplemented with 1X B27 (Invitrogen; Thermo Fisher Scientific, Inc.), 20 ng/ml human recombinant epidermal growth factor (Sigma-Aldrich; Merck KGaA) and $20 \mathrm{ng} / \mathrm{ml}$ basic fibroblast growth factor (Sigma-Aldrich; Merck KGaA) (17). The spheres were cultured at $37^{\circ} \mathrm{C}$ in humidified air containing $5 \% \mathrm{CO}_{2}$. To calculate the forming efficiency, following 7 days post-plating, spheres with diameters $>50 \mu \mathrm{m}$ were scored under an inverted microscope (Leica Microsystems). The forming efficiency $(\%)=$ scored sphere number / total plating CRC cells. For serial passage experiments, at 7 days post-plating, spheres were trypsinized as aforementioned. Single sphere-derived cells were then replated in SCM for a new round of sphere forming assay.

Animal experiments. Female, 4- to 6-week-old NOD/SCID mice $(n=135)$ were purchased from Beijing HFK Bioscience Co., Ltd. (Beijing, China) and were maintained according to protocols approved by the Institutional Animal Care and Use Committee, Huazhong University of Science and Technology (Hubei, China; IACUC ID: 2014S652). During experimentation, all mice were kept in the animal center of the Tongji Medical college, Huazhong University of Science and Technology under specific pathogen-free (SPF) conditions (License Number: SYXK\#2016-0057). For maintenance of mice, a stable breeding environment was provided: a $12-\mathrm{h} / 12-\mathrm{h}$ light/dark, a temperature of $21^{\circ} \mathrm{C}$ and a relative humidity $50 \%$ and allowed access to water and food ad libitum. For the establishment of patient-derived xenografts (termed PDXs), $\mathrm{n}=40$ mice were used, and the detailed information of PDX generation is presented in Table SI. For transplantation assays ( $n=5$ mice were used), the single cells derived from CRC6 specimens and the corresponding organoids and spheres generating form them were resuspended in a PBS/Matrigel (BD Biosciences) mixture (1:1 volume) $(15,17)$. The cells were then injected into the subcutaneous tissue of mouse flanks using 27-gauge needles at at dose of 125,000 cells/point. For histopathological analyses, the xenografts derived from primary cells (termed PDX, 1 mice), organoid cells (termed ODX, 2 mice) and sphere cells (termed SDX, 2 mice) were harvested on day 30 post-implantation. The mice were anesthetized and sacrificed according to the AVMA guidelines, and hematoxylin and eosin (H\&E) staining was performed as previously described (15). For limited dilution assays $(n=90$ mice were used), 10,000, 1,000 and 100 single cells derived from organoids at 1st - 3rd generation, or 1,000, 100 and 10 single cells derived from spheres at 1st - 3rd generation were implanted per injection (5 mice for each dose at each group). For the limited dilution assays, the tumor volumes were examined every 3 days, and the mice with excessive weight loss (humane endpoint) post-injection were excluded 
from the study and euthanized $(n=7)$, and these included: 1 mouse injected with organoid cells at 1st generation; 2 mice injected with organoid cells at 2nd generation; 4 mice injected with organoid cells at 3 rd generation. Following sacrifice, tumors were removed from the mice and weighed to evaluate tumor development. The frequency of tumor-initiating cells and statistical significance were examined using the Extreme Limiting Dilution Analysis software (bioinf.wehi.edu. au/software/elda/index.html).

Immunofluorescence. The immunofluorescence procedures for organoids and spheres were performed as previously described (19). Prior to staining, organoids or spheres were fixed in $4 \% \mathrm{PFA}$ at $4^{\circ} \mathrm{C}$ for $20 \mathrm{~min}$. For immunofluorescence staining, the following antibodies were used to detect antigens: Mouse-anti-human cluster of differentiation (CD)-133 (1:100; cat. no. 66666-1-1g; ProteinTech Group, Inc., Chicago, IL, USA) and rabbit-anti-human cytokeratin (CK)-20 (1:100; cat. no. 13063; Cell Signaling Technology, Inc., Danvers, MA, USA). Briefly, the sections were blocked with $5 \%$ (w/v) bovine serum albumin (Invitrogen; Thermo Fisher Scientific, Inc.) in PBS, then incubated with the primary antibodies at $4^{\circ} \mathrm{C}$ overnight, followed by staining with secondary antibodies conjugated to Streptavidin-Cy3 (1:100; cat. no. SA1010; Thermo Fisher Scientific, Inc.) or Alexa Flour 488 (1:100; cat. no. 705-546-147; Jackson ImmunoResearch Laboratories, Inc., West Grove, PA, USA) at room temperature for $2 \mathrm{~h}$. Finally, nuclei were stained with 4',6-diamidino-2-phenylindole (DAPI, Sigma-Aldrich Merck KGaA) at room temperature for $10 \mathrm{~min}$. Images of organoids and spheres were captured under a fluorescence microscope (TRRFM; Olympus Corp., Tokyo, Japan) or a confocal microscope (FV1000; Olympus Corp.).

Reverse transcription-quantitative polymerase chain reaction $(R T-q P C R)$. Total RNA was extracted using RNAiso Plus (Takara Bio, Inc., Otsu, Japan), and then cDNA was synthesized using the Mixima First Strand cDNA Synthesis kit (Thermo Fisher Scientific, Inc.). RT-qPCR analysis was conducted using an ABI PRISM 7300 Sequence Detection System instrument with Maxima SYBR-Green/ROX qPCR Master Mix (Thermo Fisher Scientific, Inc.) according to the manufacturer's instructions. The thermocycling conditions for RT-qPCR were: step1: $50^{\circ} \mathrm{C}$ for $2 \mathrm{~min}$; step $2: 95^{\circ} \mathrm{C}$ for $2 \mathrm{~min}$; step 3 (x40 cycles): $95^{\circ} \mathrm{C}$ for $15 \mathrm{sec}$ and $60^{\circ} \mathrm{C}$ for $1 \mathrm{~min}$. The Glyceraldehyde-3-phosphate dehydrogenase (GAPDH) was used as an internal control, and the gene expression was normalized to the GAPDH to calculate relative expression level using the $2^{-\Delta \Delta C q}$ method (20). The sequences of the primers were as follows: GAPDH forward, 5'-TCGTGGA AGGACTCATGACC-3' and reverse, 5'-TCCACCACCCTGTT GCTGTA-3'; CD44 forward, 5'-AGCAACCAAGAGGCAAG AAA-3' and reverse, 5'-GTGTGGTTGAAATGGTGCTG-3'; CD133 forward, 5'-TTCTTGACCGACTGAGACCCA-3' and reverse, 5'-TCATGTTCTCCAACGCCTCTT-3'; ABCG2 forward, 5'-TCCATATCGTGGAATGCTGA-3' and reverse, 5'-TTTCAGCCGTGGAACTCTTT-3.

Lentiviral reporter assays. The TCF/LEF reporter, which drives the expression of GFP (TOP-GFP) lentivirus, was purchased from SBO Medical Biotechnology Co. (Shanghai, China) (18).
Primary cancer cells were infected as previously described (21). Primary cells were infected with TOP-GFP lentivirus at an MOI of 25 for $72 \mathrm{~h}$. To separate the $\mathrm{GFP}^{+} / \mathrm{GFP}$ - cells, the top $\left(\mathrm{GFP}^{+}\right)$and bottom (GFP-) 5-10\% cells were purified out by flow cytometry. To evaluate Wnt activity, the intensity and frequency of $\mathrm{GFP}^{+}$cells were detected using a fluorescence microscope (TRRFM; Olympus Corp.) or flow cytometry according to the manufacturer's instructions of a FACS Aria II Cell Sorter (BD Biosciences) (18).

Flow cytometric analysis and purification of $\mathrm{CD} 133^{+} / \mathrm{CD} 133^{-}$ cells.Fluorescence-activated cell sorting (FACS) was performed according to the manufacturer's instructions using a FACS Aria II Cell Sorter (BD Biosciences) (18). To measure CD133 expression in the organoids and spheres, the cells were stained with phycoerythrin (PE)-conjugated mouse anti-human CD133 (1:11; cat. no. 130-090-756; Miltenyi Biotec GmbH, Bergisch Gladbach, Germany), then analyzed using a BD FACS Aria II flow cytometer (18). To separate $\mathrm{CD} 133^{+} / \mathrm{CD}{ }^{-} 3^{-}$cells in primary $\mathrm{CRC}$, tumor specimens were processed into single cells as described above (15). The cells were then stained with PE-conjugated mouse anti-human CD133 at $4^{\circ} \mathrm{C}$ for $15 \mathrm{~min}$. For purification, only the top $\left(\mathrm{CD} 133^{+}\right)$and bottom $\left(\mathrm{CD} 133^{-/ 10}\right)$ $10-20 \%$ cells were purified out (18).

Cell death analysis. The cell death of organoid- and sphere-derived cells was assessed using the Cell Counting kit-8 (CCK-8; Dojindo Molecular Technologies, Inc. Rockville, MD, USA), as well as with 5-fluorouracil (5-Fu) and oxaliplatin (OXA) treatment, which were purchased from Sigma-Aldrich (Merck KGaA). Briefly, the cells were seeded in complete medium at 30,000 cells/well in 96-well plates. Following $12 \mathrm{~h}$, the cells were treated with either 5-Fu $(1 \mu \mathrm{M})$ or OXA $(1 \mu \mathrm{M})$. After $72 \mathrm{~h}, 10 \mu \mathrm{l}$ CCK-8 solution was added to each well. The plates were then incubated at $37^{\circ} \mathrm{C}$ for $1 \mathrm{~h}$, and cell viability was determined by scanning with a microplate reader (Thermo Fisher Scientific, Inc.) at $450 \mathrm{~nm}$.

Statistical analysis. Statistical significance was calculated with SPSS Statistics 18.0 software (IBM Corp., Armonk, NY, USA). All measurement data are presented as the means \pm standard deviation of at least 3 independent experiments. The measurement data were analyzed using the Student's t-test or one-way analysis of variance followed by a Tukey's post hoc test to determine the significant differences of means in two or multiple groups $(n>2)$ comparisons. The enumeration data were analyzed using the Fisher's exact test to determine the significant differences of rates in two categories comparisons. $\mathrm{P}<0.05$ was considered to indicate a statistically significant difference.

\section{Results}

Organoids effectively simulate the tumor heterogeneity of CRC tumors in vitro. Sphere formation assay (22) and organoid culture (23) are 3D models that support the long-term expansion of primary tumor cells in vitro. In this study, to investigate whether these 3D models accurately simulate the tumor heterogeneity of CRC tumors, we generated spheres and organoids side by side using freshly surgical CRC specimens. H\&E staining revealed 
A
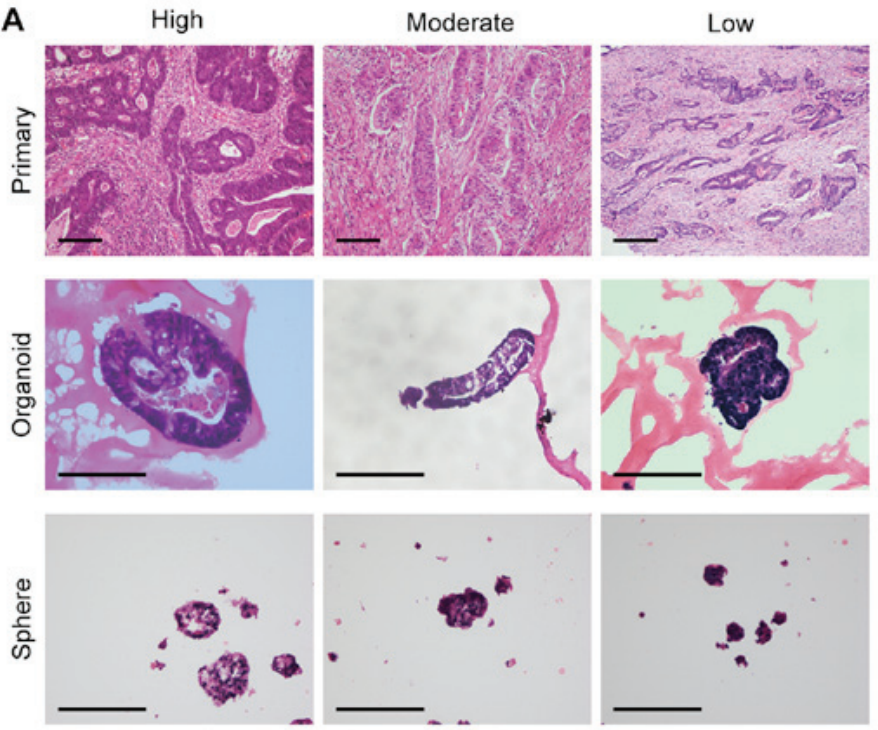

C
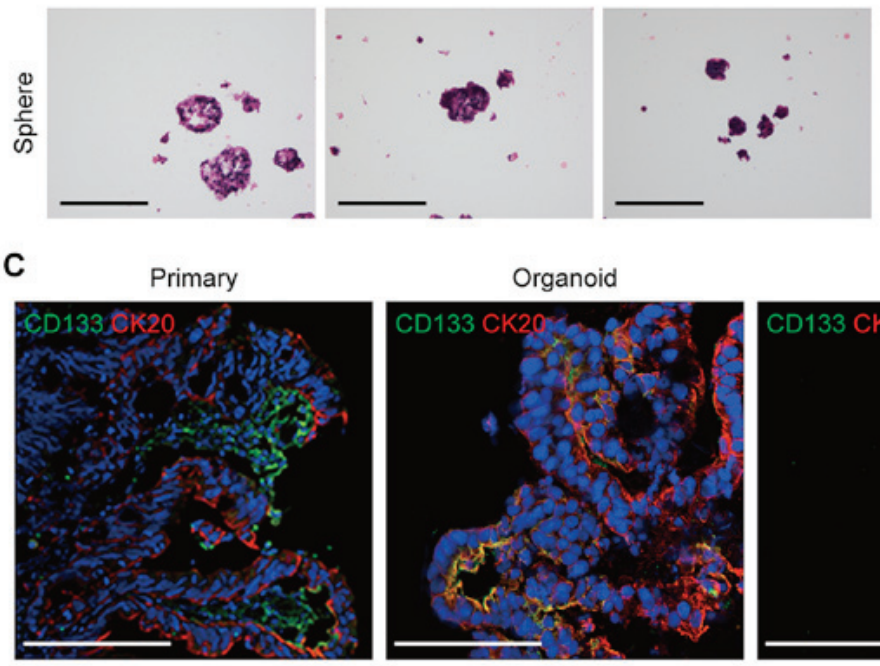
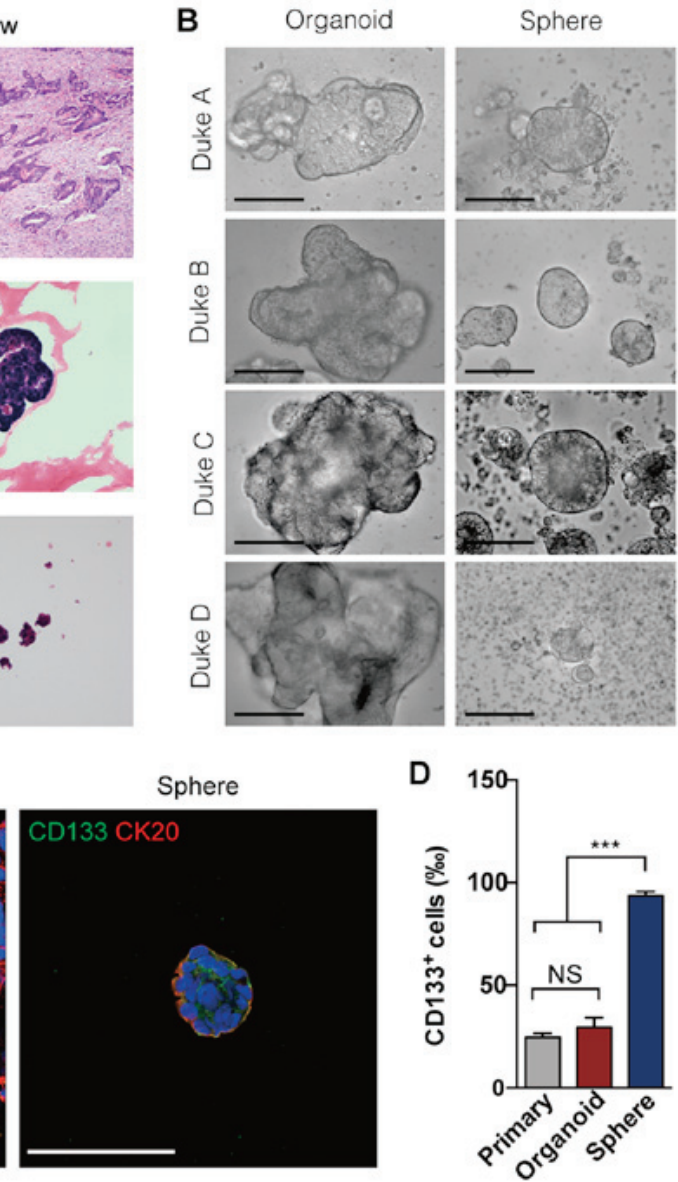

Figure 1. Organoids highly reproduce the tumor heterogeneity of CRC tumors in vitro. (A) Hematoxylin and eosin staining of primary CRCs with diagnosing tumor differentiation level at high (CRC9), moderate (CRC5) and low (CRC1), and their corresponding organoids and spheres. Scale bars, $400 \mu \mathrm{m}$. (B) Representative images of paired organoids and spheres from primary CRCs with different grades Dukes' A (CRC9); Dukes' B (CRC6); Dukes' C (CRC3); and Dukes' D (CRC1). Scale bars, $400 \mu \mathrm{m}$. (C) Immunofluorescence staining of CD133 and CK20 in primary CRCs and their corresponding organoids and spheres. Scale bars, $400 \mu \mathrm{m}$. (D) Quantification analysis of $\mathrm{CD} 133^{+}$cells in a primary CRC tumor and the corresponding organoids and spheres. ${ }^{* * *} \mathrm{P}<0.001$. The experiments shown in (C and D) were duplicated in cells derived from CRC5, CRC6 and CRC9 (n=3); the data obtained from CRC6 is presented herein. CRC, colorectal cancer; NS, not significant.

that the organoids harbored parental tumor-like budding structures, while the spheres were observed as solid globes (Fig. 1A). Notably, the organoids formed more complex structures in the cells derived from high-grade tumors (such as Dukes' C and D), whereas the spheres retained similar global shapes (Fig. 1B). Since cells expressing CD133 have been reported to enrich for CSCs in CRCs (24) and cytokeratin 20 (CK20) is a differentiated cell marker (25), the present study conducted further CD133 and CK20 staining for spheres and organoids derived from primary CRCs. The results revealed that the expression of CD133 and CK20 more closely resembled that of primary tumors in the organoids than in the spheres (Fig. 1C). Quantitative analysis demonstrated that the organoids harbored similar percentages of $\mathrm{CD}_{133^{+}}$cells when compared with the corresponding primary tumors; however, sphere-forming assays significantly increased the percentage of $\mathrm{CD} 133^{+}$cells (Fig. 1D), implying that organoid culture may maintain the cellular heterogeneity of parental CRCs. These results demonstrate that, compared with the sphere-forming assay, organoid culture may more effectively simulated the tumor heterogeneity of primary CRCs in vitro.

Organoid culturemore effectively simulates primarycolorectal tumors than sphere-forming assays. In general, tumor cells are able to generate xenografts in immuno-compromised mice subcutaneously, and the PDXs can recapitulate original tumor heterogeneity (5). In order to explore the tumor heterogeneity of CRC tumors, it is also crucial to establish successful cell culture in vitro $(5,26,27)$. However, whether cells cultured in $3 \mathrm{D}$ models preserve the ability to generate parental tumor-like xenografts (i.e., PDXs) remains unclear. Consistent with the findings of previous studies $(5,7,25)$, the results of the present study demonstrated that primary CRC cells and their corresponding organoids and spheres were all capable of generating tumor xenografts in NOD/SCID mice (Fig. 2A). To determine whether ODXs and SDXs exhibit the same tumor heterogeneity of primary CRCs, the present study performed CK20 (25) staining for primary CRC tumors, PDX, ODX and SDX. As shown in Fig. 2B, the present study revealed that the expression pattern of CK20 in ODX more closely resembled primary tumors and the corresponding PDX than SDX (Fig. 2B), suggesting that organoid culture more accurately reproduced the tumor heterogeneity of primary tumors than the sphere formation assay. In order to examine the efficiency of generating organoids or spheres from primary CRC tumors, the present study performed side-by-side organoid culture and sphere-forming assays for CRC specimens (Table S1). The 
A

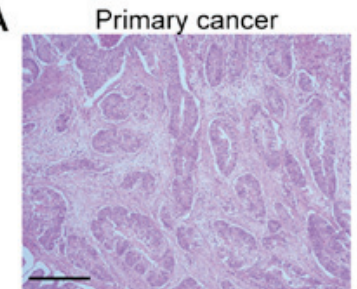

B
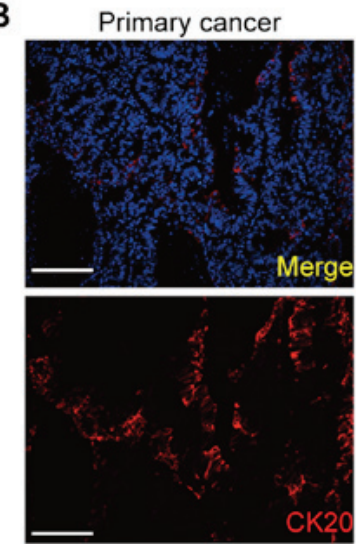

PDX

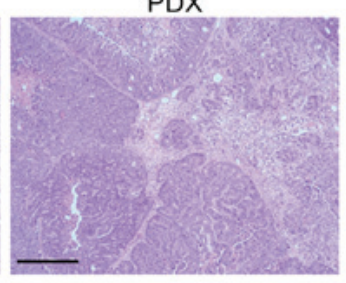

PDX
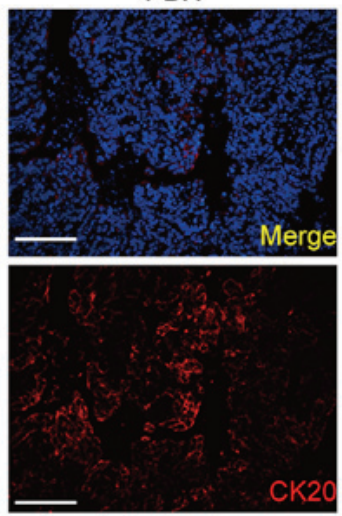

ODX

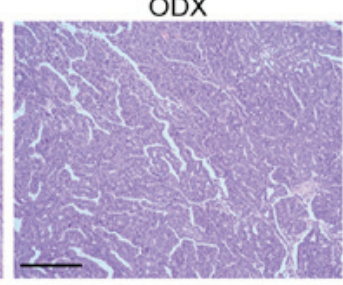

ODX
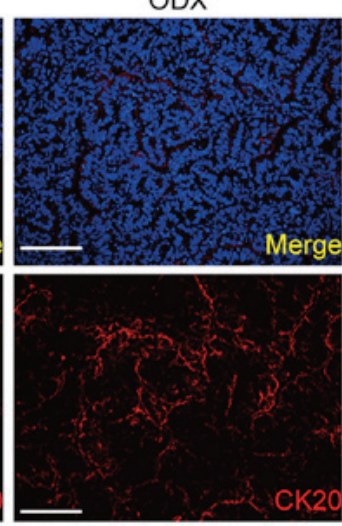

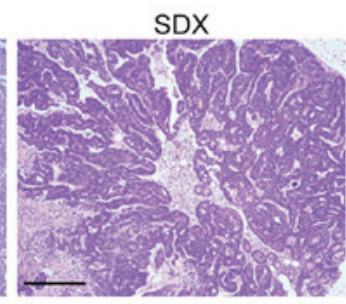

SDX

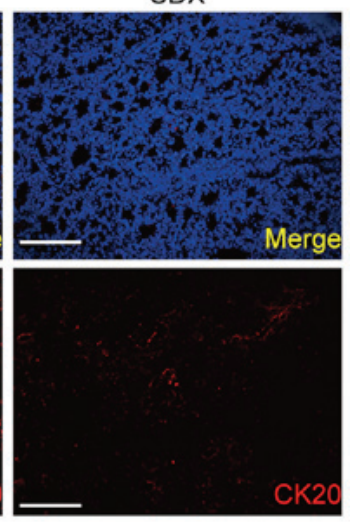

C
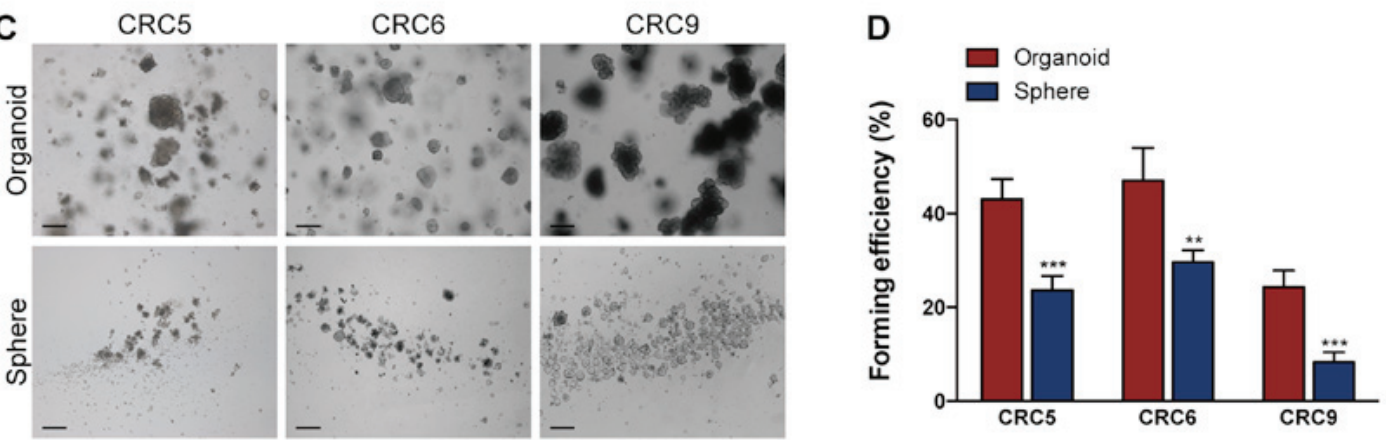

Figure 2. Organoid culture possesses a better efficiency to reproduce primary colorectal tumors than sphere-forming assay. (A) Representative hematoxylin and eosin images of xenografts generated from primary CRC cells (PDX), organoid-derived cells (ODX), sphere-derived cells (SDX) and their parental tumor (primary cancer). Scale bars, $100 \mu \mathrm{m}$. (B) Immunofluorescence staining of CK20 in a primary CRC tumor and its corresponding PDX, ODX and SDX. Scale bars, $200 \mu \mathrm{m}$. The nuclei of CRC cells were counterstained with DAPI, and the 'Merge' in top panel of (B) indicates the merging of DAPI (in blue) for nuclei and CK20 (in red) for differentiated CRC cells. The cells used in (A and B) were derived from CRC6. (C) Representative images of organoids and spheres derived from primary CRCs (CRC5, CRC6, and CRC9). (D) A total of 1,000 single purified primary CRC cells per well were respectively processed for the sphere-forming assay and organoid culture; 7 days later, the organoids or spheres were photographed in $(\mathrm{C})$. Then, the organoid- or sphere-forming efficiency of primary CRCs were quantified. ${ }^{* *} \mathrm{P}<0.01$ and ${ }^{* * * *} \mathrm{P}<0.001$. CRC, colorectal cancer; PDX, xenografts of primary CRC cells; ODX, xenografts of organoid-derived cells; SDX, xenografts of sphere-derived cells; CK20, cytokeratin 20.

results revealed that organoids in 15 of the $20 \mathrm{CRC}$ specimens were successfully generated (success rate, $75 \%$ ), whereas spheres were only generated for 5 of the $16 \mathrm{CRC}$ specimens (success rate $31 \%$; Tables I and S1). Notably, the primary CRC cells formed more organoids than spheres when the same cell dosage was applied (Fig. 2C and D). Taken together, these results demonstrate that organoid culture possesses a higher success rate and better efficiency to simulate primary colorectal tumors than sphere-forming assay.

Organoid culture maintains the number of CSCs during serial passages. The cell surface marker, CD133, is widely used to enrich CSCs in CRCs $(16,23)$. In the present experimental system, using FACS, CRC cells expressing high levels of CD133 $\left(\mathrm{CD} 133^{+}\right)$and those expressing little or no CD133 $\left(\mathrm{CD} 133^{-}\right)$were assessed and sorted. $\mathrm{CD} 133^{+} \mathrm{CRC}$ cells were found to produce more spheres and organoids than CD133 cells, implying that sphere- and organoid-forming cells were
Table I. Success rates of organoid culture model, sphere culture model and PDX model in culturing primary CRC cells.

\begin{tabular}{lccc}
\hline & Success & Failure & Success rate (\%) \\
\hline Organoid model & 15 & 5 & 75 \\
Sphere model & 5 & 11 & 31.25 \\
PDX model & 4 & 12 & 25 \\
P-value & & 0.008588 \\
organoid vs. sphere & \multicolumn{3}{|}{0.003182} \\
P-value & \multicolumn{3}{|}{} \\
organoid vs. PDX & & \\
\hline
\end{tabular}

Tumor specimens were obtained from colorectal cancer patients and processed into single cell suspensions. Cells were then seeded in 3D culture conditions to generate spheres, organoids in vitro and implanted into NOD/SCID mice to generate PDXs in vivo. P-values are listed comparing two categories using Fisher's exact test. 
A

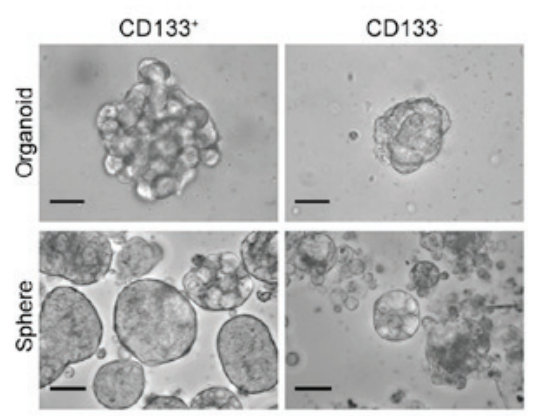

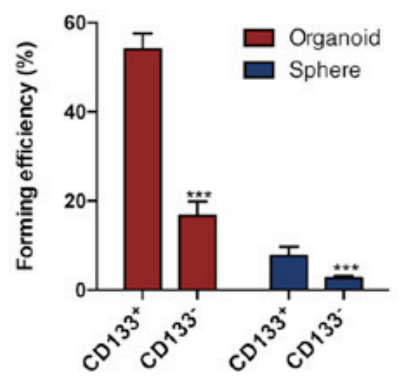

B
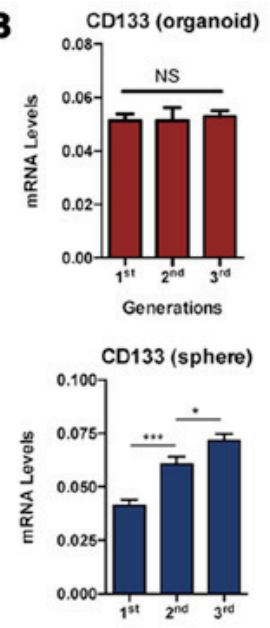

Generations
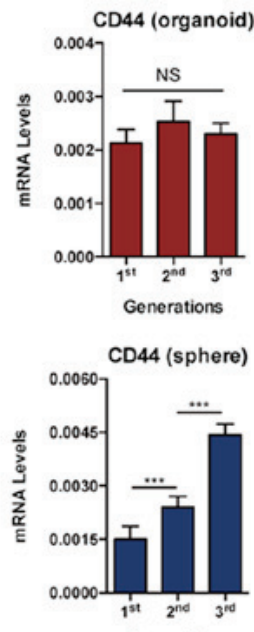

Generations
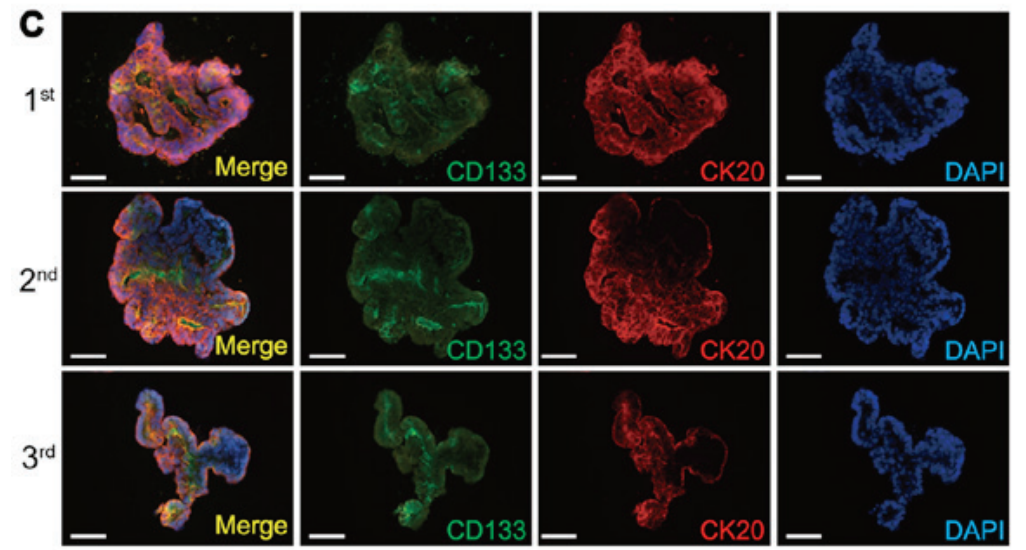

E

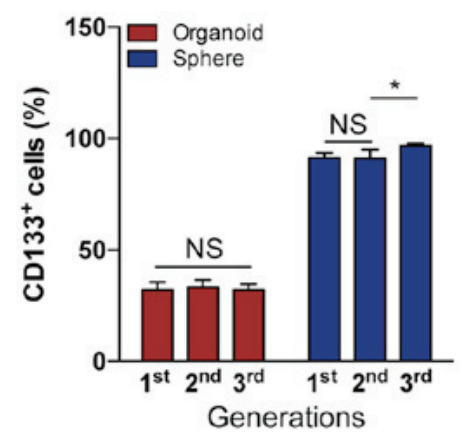

F
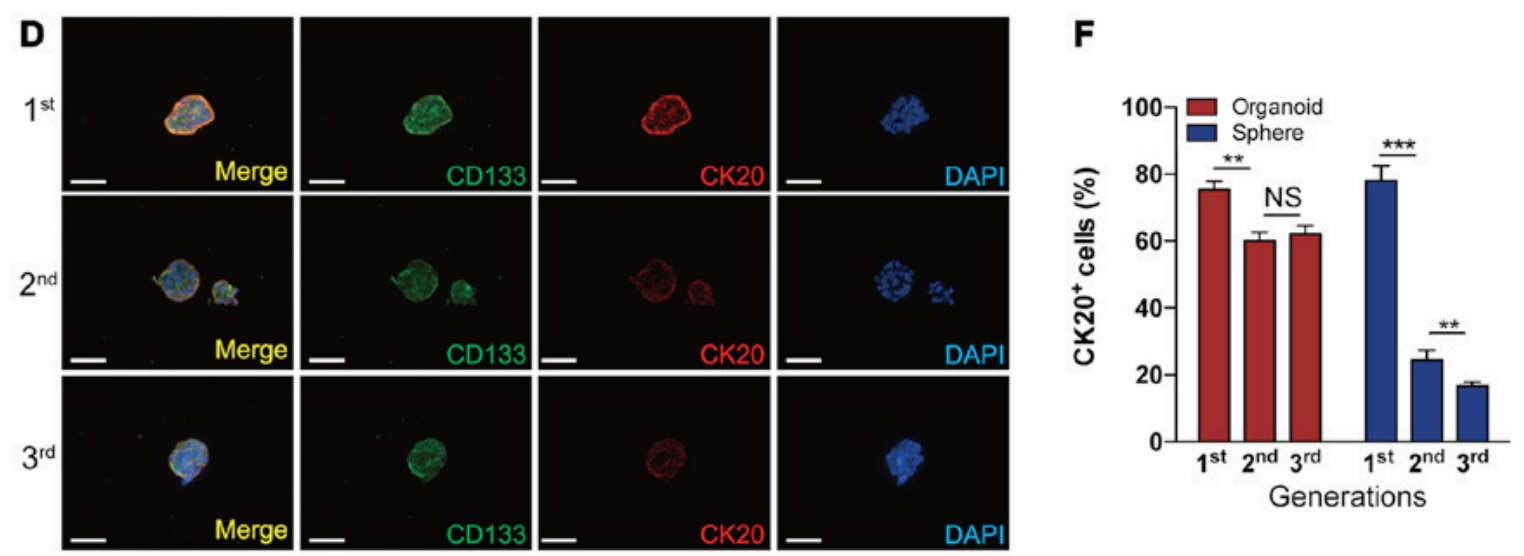

Figure 3. Organoid culture maintains the proportion of cancer stem cells during serial passages. (A) Organoids or spheres generated from purified CD133 ${ }^{+}$and CD133 CRC cells. ${ }^{* * *} \mathrm{P}<0.001$. Scale bars, $400 \mu \mathrm{m}$. (B) Reverse transcription-quantitative polymerase chain reaction analysis of the expression of CD133 and CD44 at the mRNA level in organoid- and sphere-derived cells during serial passages. "P<0.05 and ${ }^{* * *} \mathrm{P}<0.001$. (C) Immunofluorescence staining of CD133 and CK20 in organoids during serial passages. Scale bars, $400 \mu \mathrm{m}$. (D) Immunofluorescence staining of CD133 and CK20 in spheres during serial passages. Scale bars, $400 \mu \mathrm{m}$. (E) Quantification analysis of $\mathrm{CD} 133^{+}$cells in organoids and spheres during serial passages. ${ }^{*} \mathrm{P}<0.05$. (F) Flow cytometric analysis of $\mathrm{CK} 20^{+}$ cells in organoids and spheres during serial passages. ${ }^{*} \mathrm{P}<0.05,{ }^{* *} \mathrm{P}<0.01$ and ${ }^{* * * *} \mathrm{P}<0.001$. The experiments in (A-F) were duplicated in cells derived from $\mathrm{CRC} 5$, CRC6 and CRC9 $(n=3)$; the data obtained from CRC6 are presented here. CRC, colorectal cancer; CD133, cluster of differentiation 133; CK20, cytokeratin 20; NS, not significant.

enriched for CSCs (Fig. 3A). Serial sphere formation assays are generally applied to enrich and expand CSCs (27). However, the dynamics of CSCs in serial organoid cultures remain unclear. The results of the present study revealed that the levels of CD133 and CD44, the two cell surface markers widely used to enrich CSCs in CRCs $(24,29)$, remained constant in serial organoid cultures, while they significantly and gradually increased in serial sphere formation assays, indicating that the dynamics of CSCs may differ between organoid culture and sphere-forming assays during serial passages (Fig. 3B). To visualize CSCs and differentiated cells within individual organoids and spheres during serial passages, the present study performed CD133 and CK20 immunofluorescence staining for organoids and spheres (Fig. 3C and D). Quantification analysis revealed that the proportion of $\mathrm{CD} 133^{+}$and $\mathrm{CK} 20^{+}$ cells remained relatively constant in organoids during serial 


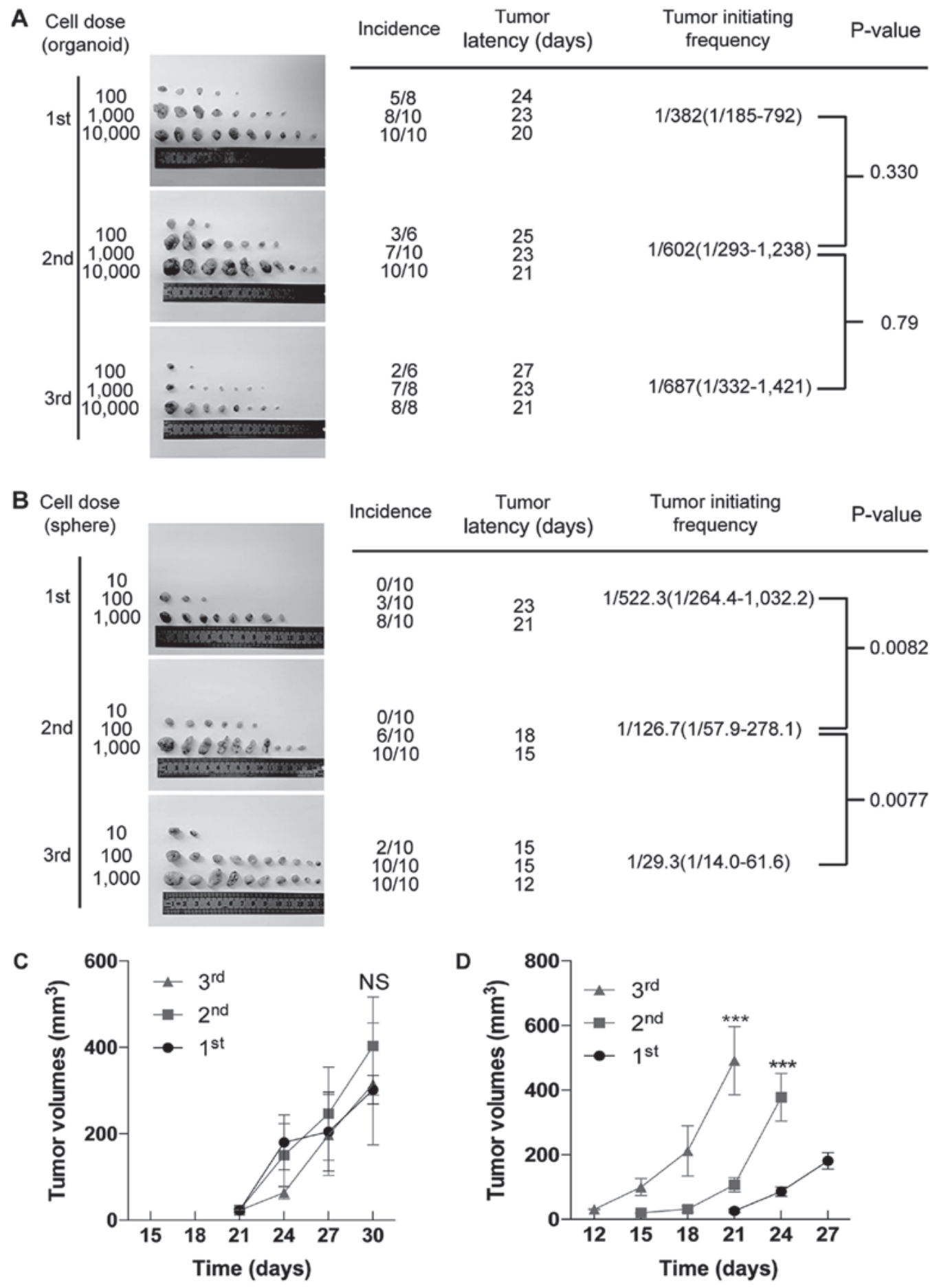

Figure 4. Organoid culture retains the frequency of tumor-initiating cells while sphere-forming assays enrich tumor- initiating cells during serial transplantations. (A and B) Limited dilution assays for serial organoid- and sphere-derived cells. The frequency of tumor-initiating cells and statistical significance were examined using Extreme Limiting Dilution Analysis software with Limdil function of the Stamod package. (http://bioinf.wehi.edu.au/software/elda/index. $\mathrm{html}$ ). (C) The cells were isolated from organoids during serial cultures, and implanted subcutaneously in NOD/SCID mice. Tumor volumes were measured in the mice with 1,000 cell injections starting from 21 days post-implantation. Data are presented as the means \pm standard deviation. (D) The cells were isolated from spheres during serial passages, and implanted subcutaneously in NOD/SCID mice. Tumor volumes were measured in the mice with 1,000 cell injections starting from 12 days post-implantation. Data are presented as the mean \pm standard deviation. ${ }^{* * *} \mathrm{P}<0.001$. The cells used in (A-D) were derived from CRC6. CRC, colorectal cancer; NS, not significant.

passages; however, there were increased levels of $\mathrm{CD}_{133^{+}}$ cells and decreased levels of $\mathrm{CK} 20^{+}$cells in spheres during serial passages (Fig. 3E and F). Taken together, these results demonstrate that organoid culture produces steady ratios of CSC subsets in long-term cultures, whereas sphere-forming assays may enrich CSCs.
Organoid culture retains the frequency of tumor-initiating cells (TICs), while sphere-forming assays enrich TICs during serial transplantations. TICs, also known as CSCs, are a rare population within CRC (30). In this study, to investigate whether the frequency of TICs was altered during serial transplantations, we performed limited dilution assays to evaluate the 

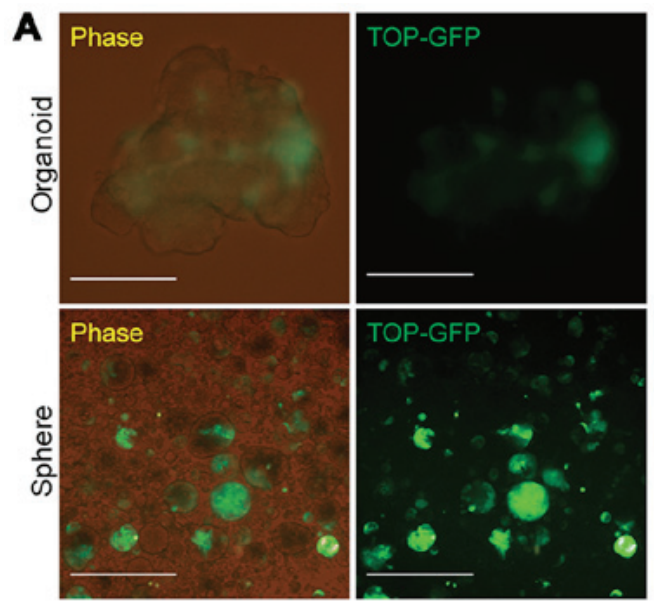

B
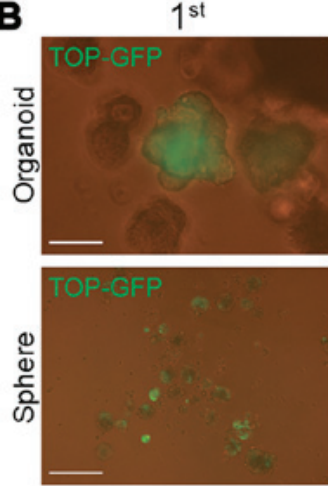

C

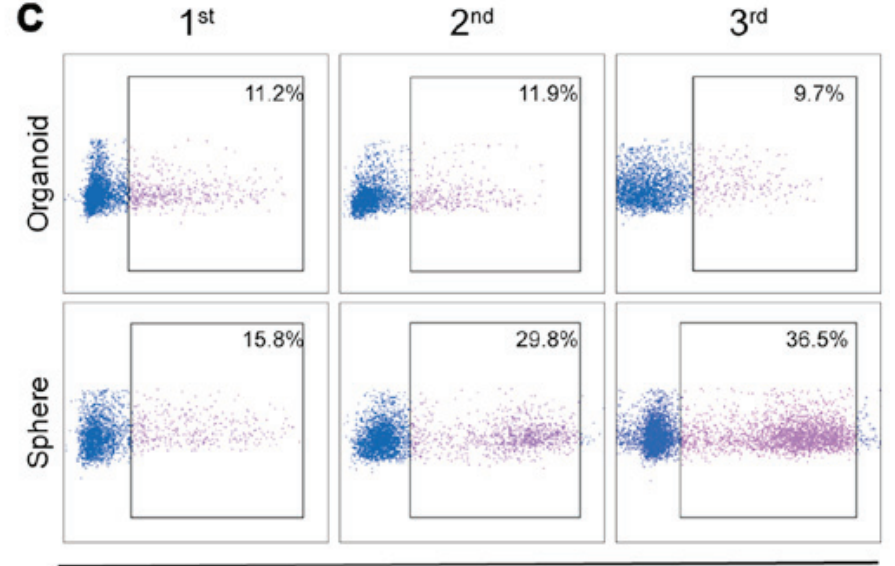

TOP-GFP

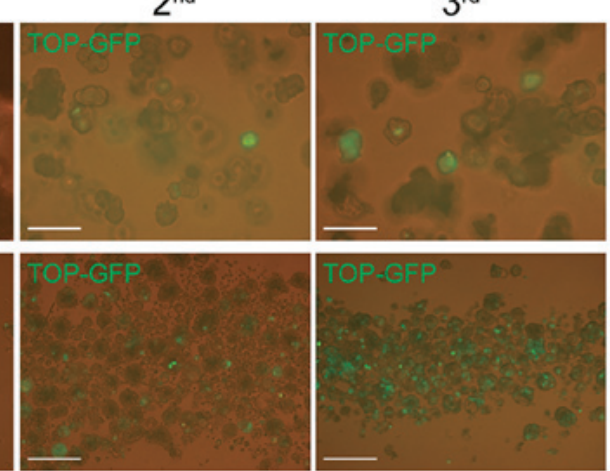

D

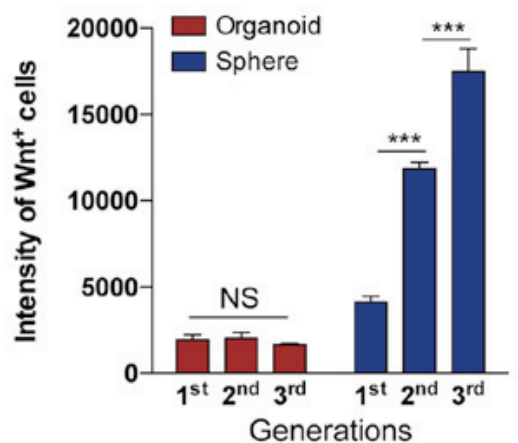

Figure 5. Serial organoid cultures preserve the proportion of $\mathrm{Wnt}^{+} \mathrm{CRC}$ cells. (A) Representative images of the intensity of GFP expression in the cells of organoids and spheres generated from the CRC cells transfected with TCF/LEF reporter lentivirus vector. Scale bars, $200 \mu \mathrm{m}$. (B) Representative images of the frequency of $\mathrm{GFP}^{+}$cells in organoids and spheres generated from the CRC cells transfected with TCF/LEF reporter lentivirus vector during serial passages. Scale bars, $100 \mu \mathrm{m}$. (C) Flow cytometric quantification analysis of $\mathrm{GFP}^{+}$cells in organoids and spheres during serial passages. (D) Quantification analysis of the intensity of $\mathrm{GFP}^{+}$cells organoids and spheres during serial passages. ${ }^{* * *} \mathrm{P}<0.001$. The experiments in (A-D) were duplicated in cells derived from $\mathrm{CRC} 5$ and CRC6; the data obtained from CRC6 are presented here. CRC, colorectal cancer; GFP, green fluorescence protein; NS, not significant.

tumorigenic capacity of organoid- and sphere-derived cells in each generation $(15,30)$. As shown in Fig. 4A, during serial transplantations (1st to 3rd), organoid-derived cells possessed a constant number of TICs. On the other hand, serial sphere-forming assays had significantly increased numbers of TICs with serial passaging (Fig. 4B). Notably, it was observed that organoid-derived cells initiated tumor generation at almost the same time in each generation, while sphere-derived cells initiated tumor generation earlier than the former generation (Fig. 4A and B). Consistent with this finding, there were no significant differences among the tumor volumes of organoid-derived xenografts in serial transplantations (Fig. 4C), while sphere-derived cells developed increasingly larger tumors in serial transplantations (Fig. 4D). Taken together, these results indicate that organoid culture maintains the frequency of TICs (i.e., CSCs) in long-term culture, while sphere-forming assays enrich TICs.

Serial organoid cultures preserve the proportion of $\mathrm{Wnt}^{+}$ CRC cells. It has been demonstrated that a high Wnt activity functionally designates the colon CSC population (18,31-33). To further evaluate the alternations in Wnt activity during serial passages, in the present study, we infected purified primary CRC cells with lentivirus, in which the TCF/LEF reporter drove the expression of GFP (TOP-GFP) and represented the cellular levels of Wnt activity $(18,31,32)$. The transfected cells were then utilized in organoid culture and sphere-forming assay; when the organoids and spheres were growing, the expression of GFP was evaluated. The results revealed that the intensity of GFP expression was stronger in the spheres than the organoids (Fig. 5A), indicating that spheres were more highly enriched for CSCs than organoids during culture. The present results also demonstrated that during serial passage, the number of cells expressing GFP (i.e., $\mathrm{GFP}^{+}$or $\mathrm{Wnt}^{+}$ cells) gradually increased in serial sphere-forming assays, but remained relatively constant in serial organoid cultures (Fig. 5B and C). Consistent with these findings, FACS analysis further demonstrated that the intensity of $\mathrm{Wnt}^{+}$cells remained unaltered in organoids during serial passaging, while they markedly increased in spheres with serial passaging (Fig. 5D). Collectively, these data indicated that organoid cultures preserved relatively constant numbers of $\mathrm{Wnt}^{+}$cells and the level of Wnt signaling in the cells during long-term culture, whereas the sphere-forming assay enriched $\mathrm{Wnt}^{+}$cells and increased the intensity of Wnt signaling in the cells.

Organoid culture preserves chemoresistant cells over time. As the presence of CSCs and the activation of Wnt signaling have been demonstrated to be associated with the chemoresistance of tumor cells (31-33), we hypothesized assumed that serial 
A

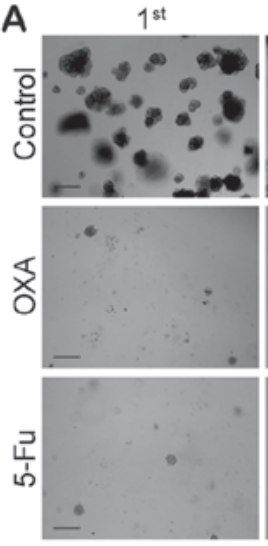

B
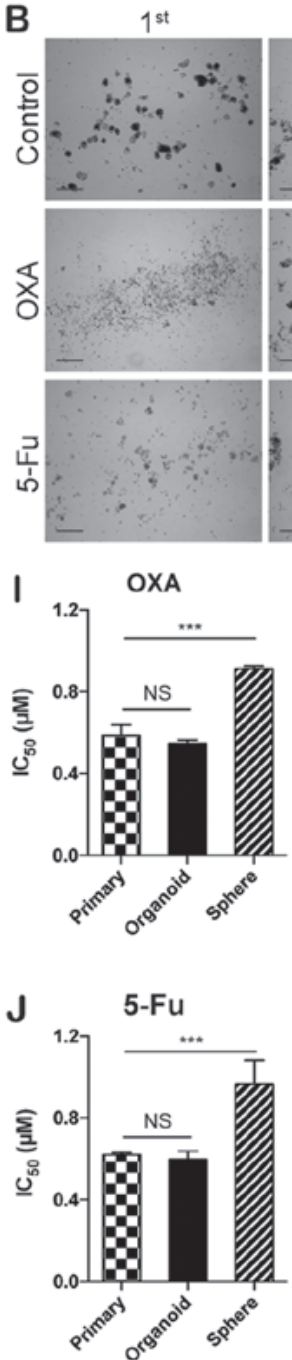

$2^{\text {nd }}$

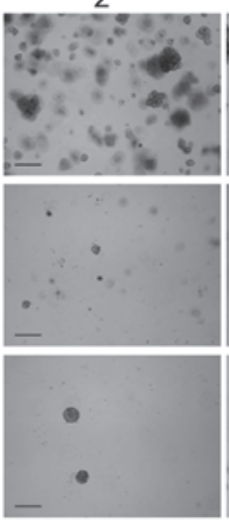

$2^{\text {nd }}$

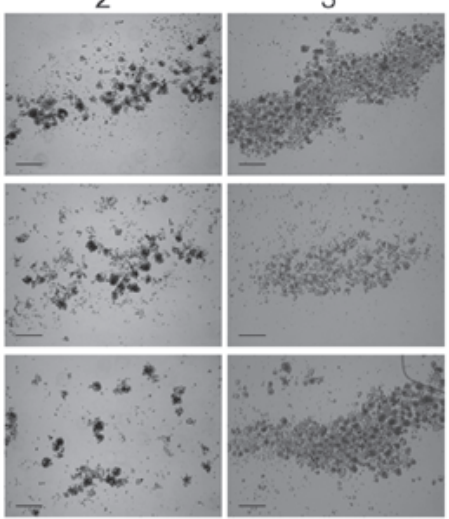

C

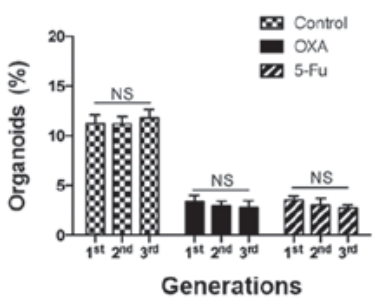

E

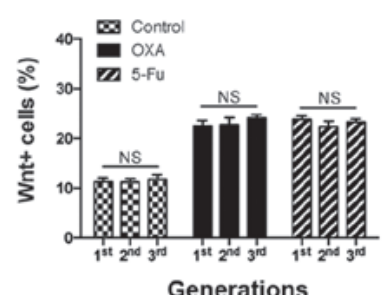

G

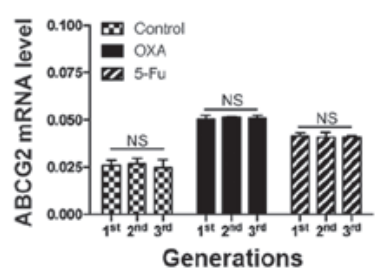

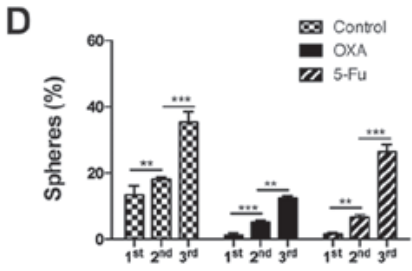

Generations

F

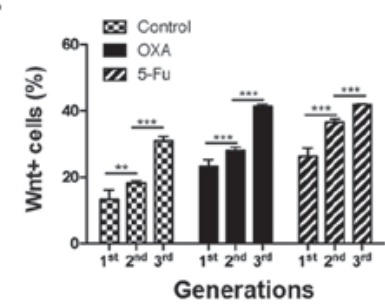

$\mathrm{H}$

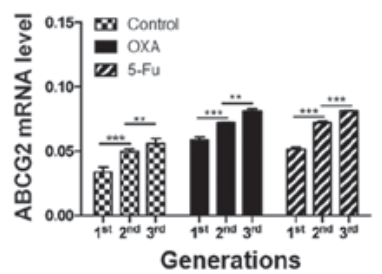

K
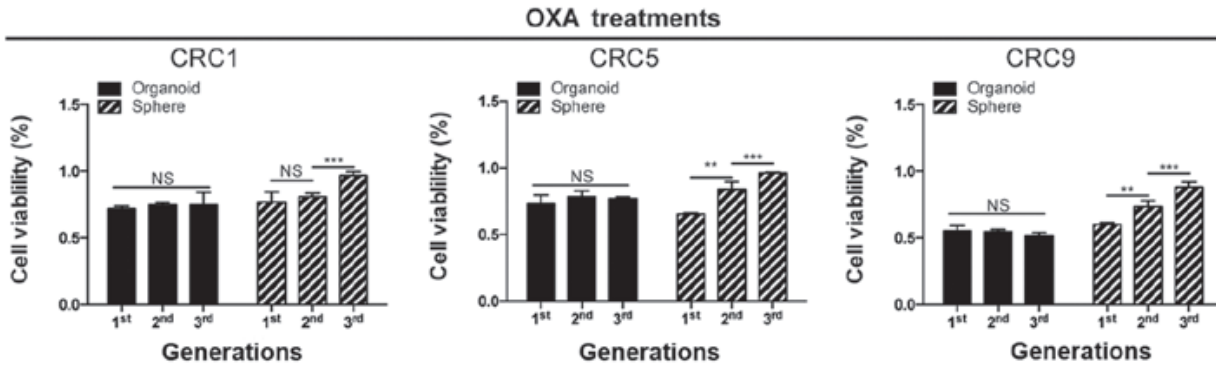

L

5-Fu treatments
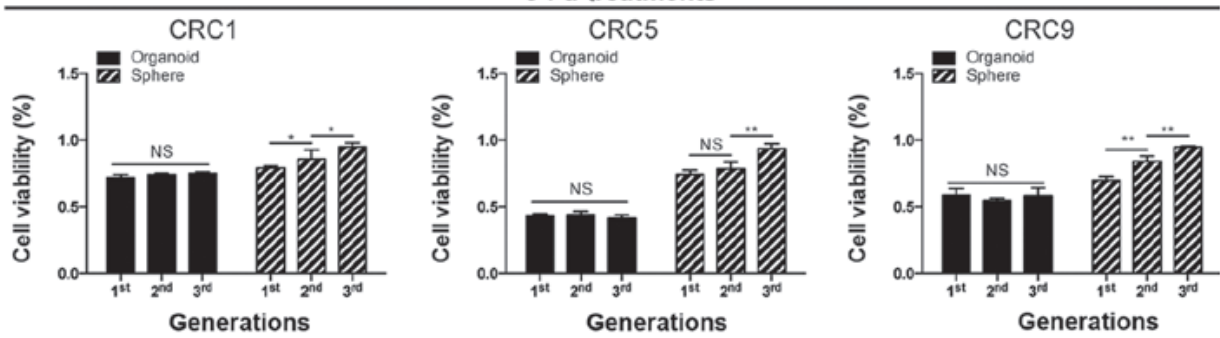

Generations

Figure 6. Organoid culture preserves chemoresistant cells over time. Representative images of (A) organoids and (B) spheres treated with chemotherapeutic agents ( $1 \mu \mathrm{M}$ OXA or $1 \mu \mathrm{M}$ 5-Fu) during serial passages. Scale bars, $200 \mu \mathrm{m}$. (C) Organoid-forming efficiency in the serial organoid cultures and (D) sphere-forming efficiency in the serial sphere formation assays upon the administration of chemotherapeutic agents $\left(1 \mu \mathrm{M} \mathrm{OXA}\right.$ or $1 \mu \mathrm{M} 5$-Fu). ${ }^{* *} \mathrm{P}<0.01$ and ${ }^{* * * *} \mathrm{P}<0.001$. Flow cytometric quantification analysis of $\mathrm{Wnt}^{+}$cells in the serial (E) organoid cultures and (F) sphere formation assays upon administration of chemotherapeutic agents $(1 \mu \mathrm{M}$ OXA or $1 \mu \mathrm{M} 5-\mathrm{Fu})$. (G) Reverse transcription-quantitative polymerase chain reaction analysis of expression of ABCG2 at the mRNA level in the serial $(\mathrm{G})$ organoid cultures and $(\mathrm{H})$ sphere formation assays upon the administration of chemotherapeutic agents $(1 \mu \mathrm{M}$ OXA or $1 \mu \mathrm{M}$ 5-Fu). ${ }^{* *} \mathrm{P}<0.01$ and ${ }^{* * * *} \mathrm{P}<0.001$. Quantification of the $\mathrm{IC}_{50}$ of primary cells, organoid and spheres of CRC upon (I) OXA $(1 \mu \mathrm{M})$ and $(\mathrm{J}) 5$-Fu $(1 \mu \mathrm{M})$ treatment. The primary CRC cells used in (A-J) were derived from CRC6. (K) The cell viability of CRC1, CRC5, and CRC9 derived organoids or spheres treated with (K) OXA $(1 \mu \mathrm{M})$ and (L) 5-Fu $(1 \mu \mathrm{M})$ during serial passages. ${ }^{*} \mathrm{P}<0.05,{ }^{* *} \mathrm{P}<0.01$ and ${ }^{* * * *} \mathrm{P}<0.001 . \mathrm{IC}_{50}, 50 \%$ inhibitory concentration. CRC, colorectal cancer; OXA, oxaliplatin; 5-Fu, 5-fluorouracil; ABCG2, adenosine triphosphate binding cassette subfamily G member 2; NS, not significant.

sphere-forming assays, which increased the proportion of CSCs and improved the levels of Wnt signaling during serial passages, may also increase the frequency of chemoresistant cells; whereas, organoid culture may only maintain the chemoresistant capacity in the cells during serial passages. To examine this hypothesis, the present study performed 
serial organoid cultures or sphere-forming assays combined with conventional chemotherapeutic agents (oxaliplatin or 5-fluorouracil), and then detected the efficiency of organoid or sphere formation. As shown in Fig. 6A-D, the results indicated that, upon the administration of chemotherapeutic agents, the efficiency of organoid and sphere formation decreased; however, along with serial passages, this impairment was partially rescued in serial sphere-forming assays, but remained unchanged in organoid culture. Furthermore, in each generation, the present study detected the frequency of $\mathrm{Wnt}^{+}$cells and the expression levels of adenosine triphosphate binding cassette subfamily $\mathrm{G}$ member 2 (ABCG2), one of the resistant markers of CRC (34), in organoids and spheres treated with chemotherapeutic agents. The results verified that, the frequency of $\mathrm{Wnt}^{+}$cells, as detected by FACS, and the expression level of ABCG2, as determined by RT-qPCR, significantly increased in spheres and organoids following treatments with chemotherapeutic agents; however, during serial passaging, these markers remained unaltered in the organoid culture, while they gradually increased with serial sphere formation (Fig. 6E-H). The half-maximal inhibitory concentration $\left(\mathrm{IC}_{50}\right)$ analysis upon OXA and 5-Fu treatment suggested that, since the 1st generation, organoid cells exhibited a similar $\mathrm{IC}_{50}$ to that of primary cells, while the sphere forming assay significantly increased the original $\mathrm{IC}_{50}$ (Fig. 6I and $\mathrm{J}$ ). These data, obtained from CRC6, indicated that organoid culture preserved the characteristics of chemoresistance in primary CRC cells. To verify the universality, a chemoresistance assay in serial passages was respectively performed in CRC1, CRC5 and CRC9. The subsequent CCK8 assay further demonstrated that the frequency of chemoresistant cells gradually increased in serial sphere-forming assays, while it remained relatively constant in serial organoid cultures (Fig. 6K and L). Overall, the results indicated that, when compared with sphere-forming assays, organoid culture can preserve the frequency of chemoresistant tumors cells in the long-term culture, and may serve as a better pre-clinical model for drug screening and discovery.

\section{Discussion}

Preclinical models are essential for assessing tumor progression and designing therapeutic approaches (5). For decades, using numerous in vitro and in vivo preclinical models, the identification of oncogenes and tumor suppressor genes, aberrant signaling pathways and interactions in tumor microenvironment, have yielded several novel therapeutic strategies, including monoclonal antibodies, chemotherapy, small molecule inhibitors and immune therapy (5). However, previous studies have indicated that the inability of preclinical models to simulate tumor heterogeneity contributed to the failure of treatments $(5,26,27)$. To avoid senseless trials and achieve better efficacy, the advantages and/or limitations of various preclinical models must be elucidated, and a relatively robust platform for drug testing must be determined.

To date, the widely used preclinical models have comprised of PDX, 2D monolayer cells culture (i.e., adherent cell culture and clonal culture) and 3D culture models (i.e., sphere formation assay and organoid culture) (5). For the PDX model, it has been demonstrated that the histopathology and genome mutational landscapes of patients can be highly preserved in the established individual PDXs (35), and the drug design procedures based on PDXs can partially predict patient response (36). Nonetheless, several limitations of PDX models impair its utilization, including the following: i) Limited success rate of initiation; ii) the lack of tumor-host interactions and immunity in xenograft animals; iii) it is highly labor intensive and time consuming; and iv) there are many ethical issues involving the use of animals (5,37). For 2D monolayer cells culture, there are several practical advantages: i) Immortalized cancer cell lines are easy to propagate, and can easily process transfection and genomic modification; and ii) the investigation concerning oncogenic pathways relies heavily on cell lines based on their stable manipulation (5). However, 2D monolayer cell culture possesses very low successful initiation rates for primary cells ( $<10 \%$ in CRC), and most notably, 2D culture fails to represent the tumor heterogeneity of primary cancers, which finally leads to the loss of the original clinical characteristics of tumor cells during long term passaging $(26,27)$.

To overcome the limitations of PDX and 2D cell culture, in recent years, numerous novel 3D culture models have been applied. Among the 3D culture models, the two most popular ones are, the sphere formation assay and organoid culture $(5,26,27)$. 3D culture models are considered to more accurately simulate the tumor heterogeneity of primary tumors when compared with 2D cell culture, and be less time-consuming and expensive than PDX (5). In general, sphere formation assays can be applied to enrich cancer cells with limited or unlimited self-renewal capacity for primary tumor cells and cell lines (38); on the other hand, organoid culture has been utilized in a range of cancer studies including drug testing, disease modeling, and co-culture models of cancer and stromal cells (11-14,39-41). Although the two $3 \mathrm{D}$ culture models can support the continuous expansion of primary tumor cells, whether they maintain the self-renewal capacity of cells in long-term culture, which is critical to simulate the tumor heterogeneity of primary tumors, remains largely uncertain.

It has been revealed that the tumor bulk harbored cellular hierarchy with CSCs at the apex, possessing self-renewal capacity and multi-differentiated potential (42). CSCs were considered to be closely associated with tumor heterogeneity in cancers, particularly in CRCs (43). Based on the expression of cell surface markers (such as CD133 and CD44) and the activity of Wnt signaling in CRC cells, it has been demonstrated that CSCs are enriched in the cells that highly express such markers or possess high activity of Wnt signaling (43). Furthermore, transplantation assays are applied to test the self-renewal capacity of CSCs in vivo $(42,44)$. In the present study, the proportion of CSCs (including $\mathrm{CD} 133^{+}, \mathrm{CD}_{4} 4^{+}$and $\mathrm{Wnt}^{+}$cells) was enriched in serial sphere formation assays, but maintained constant in serial organoid culturing. Notably, following transplantation assays, the results demonstrated that serial sphere forming assays expanded CSCs (including CSCs and TICs), while serial organoid passage maintained the original levels. In addition, the results further demonstrated that cellular heterogeneity in organoids more closely resembled that of the primary tumor and the corresponding PDX than in spheres.

Sphere formation assay and organoid culture are both candidates of preclinical drug testing models (9). In previous 
studies, a sphere-forming assay has been used to evaluate CSCs, the putative inherent chemoresistant cells $(38,45)$. However, several studies have suggested that, during the sphere formation assay, as the CSCs become enriched, the drug activity of cancer cells became unstable $(10,28)$. On the other hand, organoid culture, with high efficiency to establish patient-derived organoids (PDOs), enabled patient-specific drug testing and the development of personalized treatments (11-14). Although PDOs have been applied in drug testing in various types of solid tumors, whether organoid culture maintains the chemoresistant capacity of primary tumor cells in the long-term culture remains largely unknown. The present results demonstrated that the frequency of chemoresistant cells was constant in serial organoid cultures, whereas it gradually increased in the serial sphere-forming assays.

In conclusion, taken together with previous findings, the results of the present study demonstrated that organoid culture is the better preclinical model for reproducing tumor heterogeneity and testing drug responses, especially in long-term cultures.

\section{Acknowledgements}

The authors would like to thank animal facility of Tongji Medical College for assisting with the animal experiments.

\section{Funding}

The present study was supported by grants from the National Natural Science Foundation of China (grant no. 81572894), Program for New Century Excellent Talents in University (grant no. NCET-12-0208), the Fundamental Research Funds for the Central Universities (HUST; grant no. 01-18-540005), Tongji Hospital Funds for the Returned Overseas Scientists and Outstanding Young Scientists (grant no. 2012yq004) and China Postdoctoral Science Foundation Funded Project (grant no. 2016M602313).

\section{Availability of data and materials}

All data generated or analyzed during this study are included in the article.

\section{Authors' contributions}

HZ, CY and JQ contributed to the conception and design of the study. HZ performed the majority of the experiments. JQ and HZ wrote the manuscript. JQ revised the manuscript. YH, LM, XL and DT analyzed the experimental data. HZ, KH and QL performed the animal studies. All authors have read and approved the final manuscript.

\section{Ethics approval and consent to participate}

Surgical human colorectal adenocarcinoma samples were obtained with written informed consent under guidelines approved by Institutional Review Board of Tongji Hospital, Tongji Medical College, Huazhong University of Science and Technology, (Hubei China; IRB ID: 20141106), conducted according to the principles of the Declaration of Helsinki. The mice used in the present study were maintained according to guidelines approved by Institutional Animal Care and Use Committee, Huazhong University of Science and Technology (Hubei China; IACUC ID:2014S652), and were anesthetized and sacrificed according to AVMA guidelines.

\section{Patient consent for publication}

Not applicable.

\section{Competing interests}

The authors declare that they have no competing interests.

\section{References}

1. Siegel RL, Miller KD, Fedewa SA, Ahnen DJ, Meester RGS, Barzi A and Jemal A: Colorectal cancer statistics, 2017. CA Cancer J Clin 67: 177-193, 2017.

2. O'Brien CA, Pollett A, Gallinger S and Dick JE: A human colon cancer cell capable of initiating tumour growth in immunodeficient mice. Nature 445: 106-110, 2007.

3. McGranahan N and Swanton C: Biological and therapeutic impact of intratumor heterogeneity in cancer evolution. Cancer Cell 27: 15-26, 2015

4. Zhou B-BS, Zhang H, Damelin M, Geles KG, Grindley JC and Dirks PB: Tumour-initiating cells: Challenges and opportunities for anticancer drug discovery. Nat Rev Drug Discov 8: 806-823, 2009.

5. Sachs $\mathrm{N}$ and Clevers $\mathrm{H}$ : Organoid cultures for the analysis of cancer phenotypes. Curr Opin Genet Dev 24: 68-73, 2014.

6. Visvader JE and Lindeman GJ: Cancer stem cells in solid tumours: Accumulating evidence and unresolved questions. Nat Rev Cancer 8: 755-768, 2008.

7. Vermeulen L, Todaro M, de Sousa Mello F, Sprick MR, Kemper K Perez Alea M, Richel DJ, Stassi G and Medema JP: Single-cell cloning of colon cancer stem cells reveals a multi-lineage differentiation capacity. Proc Natl Acad Sci USA 105: 13427-13432, 2008.

8. Zeuner A, Todaro M, Stassi G and De Maria R: Colorectal cancer stem cells: From the crypt to the clinic. Cell Stem Cell 15: 692-705, 2014

9. Fang Y and Eglen RM: Three-dimensional cell cultures in drug discovery and development. SLAS Discov 22: 456-472, 2017.

10. Karlsson H, Fryknäs M, Larsson R and Nygren P: Loss of cancer drug activity in colon cancer HCT-116 cells during spheroid formation in a new 3-D spheroid cell culture system. Exp Cell Res 318: 1577-1585, 2012.

11. van de Wetering M, Francies HE, Francis JM, Bounova G, Iorio F, Pronk A, van Houdt W, van Gorp J, Taylor-Weiner A, Kester L, et al: Prospective derivation of a living organoid biobank of colorectal cancer patients. Cell 161: 933-945, 2015.

12. Fujii M, Shimokawa M, Date S, Takano A, Matano M, Nanki K, Ohta Y, Toshimitsu K, Nakazato Y, Kawasaki K, et al: A colorectal tumor organoid library demonstrates progressive loss of niche factor requirements during tumorigenesis. Cell Stem Cell 18: 827-838, 2016.

13. Broutier L, Mastrogiovanni G, Verstegen MMA, Francies HE, Gavarró LM, Bradshaw CR, Allen GE, Arnes-Benito R, Sidorova O, Gaspersz MP, et al: Human primary liver cancer-derived organoid cultures for disease modeling and drug screening. Nat Med 23: 1424-1435, 2017.

14. Huang L, Holtzinger A, Jagan I, BeGora M, Lohse I, Ngai N, Nostro C, Wang R, Muthuswamy LB, Crawford HC, et al: Ductal pancreatic cancer modeling and drug screening using human pluripotent stem cell- and patient-derived tumor organoids. Nat Med 21: 1364-1371, 2015.

15. Yan C, Hu Y, Zhang B, Mu L, Huang K, Zhao H, Ma C, Li X, Tao D, Gong J, et al: The CEA-/lo colorectal cancer cell population harbors cancer stem cells and metastatic cells. Oncotarget 7: 80700-80715, 2016.

16. Sato T, Stange DE, Ferrante M, Vries RGJ, Van Es JH, Van den Brink S, Van Houdt WJ, Pronk A, Van Gorp J, Siersema PD, et al: Long-term expansion of epithelial organoids from human colon, adenoma, adenocarcinoma, and Barrett's epithelium. Gastroenterology 141: 1762-1772, 2011. 
17. Mu L, Huang K, Hu Y, Yan C, Li X, Tao D, Gong J and Qin J: Small-sized colorectal cancer cells harbor metastatic tumor-initiating cells. Oncotarget 8: 107907-107919, 2017.

18. Hu Y, Yan C, Mu L, Huang K, Li X, Tao D, Wu Y and Qin J: Fibroblast-derived exosomes contribute to chemoresistance through priming cancer stem cells in colorectal cancer. PLoS One 10: e0125625, 2015.

19. Mahe MM, Aihara E, Schumacher MA, Zavros Y, Montrose MH, Helmrath MA, Sato T and Shroyer NF: Establishment of gastrointestinal epithelial organoids. Curr Protoc Mouse Biol 3: 217-240, 2013

20. Livak KJ and Schmittgen TD: Analysis of relative gene expression data using real-time quantitative PCR and the 2(- $\Delta \Delta \mathrm{C}(\mathrm{T}))$ method. Methods 25: 402-408, 2001.

21. Fujii M, Matano M, Nanki K and Sato T: Efficient genetic engineering of human intestinal organoids using electroporation. Nat Protoc 10: 1474-1485, 2015.

22. Pastrana E, Silva-Vargas V and Doetsch F: Eyes wide open: A critical review of sphere-formation as an assay for stem cells. Cell Stem Cell 8: 486-498, 2011

23. Drost $\mathbf{J}$ and Clevers H: Organoids in cancer research. Nat Rev Cancer 18: 407-418, 2018.

24. Ricci-Vitiani L, Lombardi DG, Pilozzi E, Biffoni M, Todaro M, Peschle C and De Maria R: Identification and expansion of human colon-cancer-initiating cells. Nature 445: 111-115, 2007.

25. Shimokawa M, Ohta Y, Nishikori S, Matano M, Takano A Fujii M, Date S, Sugimoto S, Kanai T and Sato T: Visualization and targeting of $\mathrm{LGR}^{+}$human colon cancer stem cells. Nature 545: 187-192, 2017

26. Mitra A, Mishra L and Li S: Technologies for deriving primary tumor cells for use in personalized cancer therapy. Trends Biotechnol 31: 347-354, 2013.

27. Centenera MM, Raj GV, Knudsen KE, Tilley WD and Butler LM: Ex vivo culture of human prostate tissue and drug development. Nat Rev Urol 10: 483-487, 2013.

28. Portillo-Lara R and Alvarez MM: Enrichment of the cancer stem phenotype in sphere cultures of prostate cancer cell lines occurs through activation of developmental pathways mediated by the transcriptional regulator $\Delta$ Np63 $\alpha$. PLoS One 10: e0130118, 2015.

29. Lau WM, Teng E, Chong HS, Lopez KA, Tay AY, Salto-Tellez M, Shabbir A, So JB and Chan SL: CD44v8-10 is a cancer-specific marker for gastric cancer stem cells. Cancer Res 74: 2630-2641, 2014.

30. Qin J, Liu X, Laffin B, Chen X, Choy G, Jeter CR, Calhoun-Davis T, Li H, Palapattu GS, Pang S, et al: The PSA(-/lo) prostate cancer cell population harbors self-renewing long-term tumor-propagating cells that resist castration. Cell Stem Cell 10 $556-569,2012$.

31. Hu YB, Yan C, Mu L, Mi YL, Zhao H, Hu H, Li XL, Tao DD, $\mathrm{Wu}$ YQ, Gong JP, et al: Exosomal Wnt-induced dedifferentiation of colorectal cancer cells contributes to chemotherapy resistance. Oncogene: Nov 2, 2018 (Epub ahead of print) doi: 10.1038/s41388-018-0557-9.

32. Vermeulen L, De Sousa E Melo F, van der Heijden M, Cameron K, de Jong JH, Borovski T, Tuynman JB, Todaro M, Merz C, Rodermond $\mathrm{H}$, et al: Wnt activity defines colon cancer stem cells and is regulated by the microenvironment. Nat Cell Biol 12: 468-476, 2010
33. Nusse $\mathrm{R}$ and Clevers $\mathrm{H}$ : Wnt/ $\beta$-catenin signaling, disease, and emerging therapeutic modalities. Cell 169: 985-999, 2017.

34. Hsu HH, Chen MC, Baskaran R, Lin YM, Day CH, Lin YJ, Tu CC, Vijaya Padma V, Kuo WW and Huang CY: Oxaliplatin resistance in colorectal cancer cells is mediated via activation of ABCG2 to alleviate ER stress induced apoptosis. J Cell Physiol 233: 5458-5467, 2018.

35. Cassidy JW, Caldas C and Bruna A: Maintaining tumor heterogeneity in patient-derived tumor xenografts. Cancer Res 75 2963-2968, 2015.

36. Bruna A, Rueda OM, Greenwood W, Batra AS, Callari M, Batra RN, Pogrebniak K, Sandoval J, Cassidy JW, Tufegdzic-Vidakovic A, et al: A biobank of breast cancer explants with preserved intra-tumor heterogeneity to screen anticancer compounds. Cell 167: 260-274.e22, 2016.

37. Aparicio S, Hidalgo M and Kung AL: Examining the utility of patient-derived xenograft mouse models. Nat Rev Cancer 15: 311-316, 2015.

38. Singh SK, Hawkins C, Clarke ID, Squire JA, Bayani J, Hide T, Henkelman RM, Cusimano MD and Dirks PB: Identification of human brain tumour initiating cells. Nature 432: 396-401, 2004.

39. Drost J, van Boxtel R, Blokzijl F, Mizutani T, Sasaki N, Sasselli V, de Ligt J, Behjati S, Grolleman JE, van Wezel T, et al: Use of CRISPR-modified human stem cell organoids to study the origin of mutational signatures in cancer. Science 358 : 234-238, 2017.

40. Seino T, Kawasaki S, Shimokawa M, Tamagawa H, Toshimitsu K, Fujii M, Ohta Y, Matano M, Nanki K, Kawasaki K, et al: Human pancreatic tumor organoids reveal loss of stem cell niche factor dependence during disease progression. Cell Stem Cell 22: 454-467.e6, 2018.

41. Dijkstra KK, Cattaneo CM, Weeber F, Chalabi M, van de Haar J, Fanchi LF, Slagter M, van der Velden DL, Kaing S, Kelderman S, et al: Generation of tumor-reactive T cells by co-culture of peripheral blood lymphocytes and tumor organoids. Cell 174: 1586-1598.e12, 2018.

42. Batlle E and Clevers H: Cancer stem cells revisited. Nat Med 23: 1124-1134, 2017.

43. Fearon ER: Molecular genetics of colorectal cancer. Annu Rev Pathol 6: 479-507, 2011

44. Bonnet D and Dick JE: Human acute myeloid leukemia is organized as a hierarchy that originates from a primitive hematopoietic cell. Nat Med 3: 730-737, 1997.

45. Sun S, Liu S, Duan SZ, Zhang L, Zhou H, Hu Y, Zhou X, Shi C, Zhou R and Zhang Z: Targeting the c-Met/FZD8 signaling axis eliminates patient-derived cancer stem-like cells in head and neck squamous carcinomas. Cancer Res 74 7546-7559, 2014.

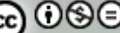

This work is licensed under a Creative Commons Attribution-NonCommercial-NoDerivatives 4.0 International (CC BY-NC-ND 4.0) License. 